\title{
EFFECT OF CHEMICAL COMPOSITION ON THE MICROSTRUCTURE, HARDNESS AND ELECTRICAL CONDUCTIVITY PROFILES OF THE Bi-Ge-In ALLOYS
}

\author{
Aleksandar Đorđevićl, Milena Premović, ${ }^{1 *}$, Duško Minić ${ }^{1}$, Milan Kolarević ${ }^{2}$, \\ Milica Tomovic ${ }^{1}$ \\ ${ }^{1}$ University of Priština, Faculty of Technical Science, Kneza Miloša 7, 38220 Kos. \\ Mitrovica, Serbia \\ ${ }^{2}$ University of Kragujevac, Faculty of Mechanical and Civil Engineering in Kraljevo, \\ Kraljevo, Serbia
}

Received 11.09.2020

Accepted 25.12.2020

\begin{abstract}
In this study, the microstructure, hardness, and electrical properties of selected ternary $\mathrm{Bi}-\mathrm{Ge}-\mathrm{In}$ alloys were investigated. Isothermal sections of the Bi-Ge-In system at 25,200 , and $300{ }^{\circ} \mathrm{C}$ were extrapolated using optimized thermodynamic parameters from the literature. The used experimental techniques include optical microscopy, X-ray powder diffraction (XRD), scanning electron microscopy (SEM) and energy dispersion spectrometry (EDS), Brinell hardness, and electrical conductivity measurements. The results of EDS phase composition analysis were compared with the calculated isothermal sections and a good overall agreement was reached. The results of the XRD were also in line with the predicted phase balance. By using ANOVA analysis and experimental results of Brinell hardness and electrical conductivity, a mathematical model was suggested for the calculation of these properties along with all composition ranges. The appropriated mathematical model was subsequently used for the prediction of hardness and electrical conductivity throughout the whole composition range.
\end{abstract} conductivity.

Keywords: phase equilibrium, mathematical model, hardness, electrical

\section{Introduction}

The ternary Bi-Ge-In system has been previously investigated by our group [1]. In our previous study, a reliable thermodynamic data set was proposed and experimentally confirmed. For Bi-Ge-In system, three vertical sections Bi-GeIn, Ge-BiIn, and In-BiGe and three isothermal sections at 50,75 , and $100^{\circ} \mathrm{C}$ were experimentally investigated [1].

${ }^{*}$ Corresponding author: Milena Premović, milena.premovic@gmail.com 
The same thermodynamic parameters obtained in a previous study [1] were used in the current study as well as Pandat software [2].

Both Bi-Ge and Ge-In based alloys have applications in the industry for making different optical and electronic devices [3-5]. Germanium-based alloys have special applications in modern technology for making optical discs, blu-ray discs, flash memory, etc. [6-8]. A very limited number of studies carried out on Bi-Ge-X alloy systems is available in the literature. Premović et al. [9] experimentally investigated phase equilibria of the ternary Bi-Ge-Sb system. The phase diagram of the ternary Bi-Ge-Ag system has been experimentally examined and calculated by Milisavljevic et al. [10]. The main motivation for studying these alloys is to contribute to the further development of their field of application. The results presented in this study should benefit the industry for the development of new alloys. On the other hand, Bi-In alloys are also interesting due to the application as thermoelectric materials [11], multicomponent lead-free solders [12, 13], etc. A large number of ternary systems based on $\mathrm{Bi}$-In are tested but not in combination with Ge. So this is another reason for this work.

\section{Experimental work}

In this study, three isothermal sections at 25,200 , and $300{ }^{\circ} \mathrm{C}$ were calculated. Thermodynamic calculations of isothermal sections were performed by using Pandat software [2]. Experimental results were obtained using scanning electron microscopy (SEM) with energy dispersive spectrometry (EDS), X-ray powder diffraction (XRD) analysis and inverted metallographic microscope. In addition, important properties such as hardness and electrical conductivity were measured.

High-purity (99.999 wt. \%) $\mathrm{Bi}, \mathrm{Ge}$, and In metals produced by Alfa Aesar (Germany) were used for the preparation of investigated alloy samples. Three series of samples were prepared i.e., 22 alloys in total. Five of the prepared samples were used for the assessment of phase equilibria at $200{ }^{\circ} \mathrm{C}$ and another five for the assessment of phase equilibria at $300{ }^{\circ} \mathrm{C}$. Nominal compositions of the samples were randomly selected. The total mass of each sample was $4 \mathrm{~g}$. Weighed masses of the samples were arc-melted and re-melted five times under a high purity argon atmosphere using a non-consumable tungsten electrode with an average weight loss of around 1 mass $\%$. After melting, three series of samples were prepared (first series annealed at $200{ }^{\circ} \mathrm{C}$, second series annealed at $300{ }^{\circ} \mathrm{C}$, and third series for electrical conductivity and hardness measurements). Samples for investigation of isothermal sections at $200{ }^{\circ} \mathrm{C}$ and $300{ }^{\circ} \mathrm{C}$ were sealed in evacuated quartz tubes and kept at $200{ }^{\circ} \mathrm{C}$ for four weeks and six weeks at $300{ }^{\circ} \mathrm{C}$. After annealing the samples were quenched in the water and ice mixture. These samples were prepared and used for SEM-EDS and XRD analysis.

The compositions of the alloy samples were determined using a JEOL JSM-6460 scanning electron microscope (SEM) and TESCAN VEGA3 scanning electron microscope, which were both equipped with an EDS system (Oxford Instruments X-act). The samples for SEM-EDS analysis were prepared by standard procedure.

Powder XRD data were recorded with a D2 PHASER in the $2 \theta$ range from $10^{\circ}$ to $75^{\circ}$ with a step size of $0.02^{\circ}$.

The last prepared group of the samples was used for light optical microscopy, XRD analysis, electrical conductivity, and hardness measurements. These samples were again melted in an electric furnace under a high-purity argon atmosphere and slowly cooled to 
room temperature using a cooling rate of $2{ }^{\circ} \mathrm{Cmin}^{-1}$ in a way to achieve equilibrium at room temperature for the hardness and electrical conductivity measurements. The obtained microstructures were inspected using XRD analysis. By using OLYMPUS GX41 optical images of the microstructures were recorded. The samples were prepared by the classic metallographic procedure. INNOVATEST and SIGMATEST 2.069 eddy instruments were used for Brinell hardness and Electrical conductivity measurements, respectively. For the Brinell hardness test, a steel ball with a diameter of $1 \mathrm{~mm}$ was used, and a load force of $294.2 \mathrm{~N}$ was applied for 20 seconds.

\section{Results and discussion}

Constitutive binary systems of the ternary Bi-Ge-In system were extensively studied in the past. Reliable thermodynamic datasets for these binary systems are available in the literature [14-16]. Based on the literature information for binary subsystems, considered phases, their crystallographic data, and database names (for the solid phases) are summarized in Table 1.

Table 1. Considered phase, their crystallographic data and database names for the solid phases of the ternary Bi-Ge-In system [14-16].

\begin{tabular}{lcccc}
\hline $\begin{array}{l}\text { Thermodynamic } \\
\text { database name }\end{array}$ & $\begin{array}{c}\text { Common } \\
\text { name }\end{array}$ & $\begin{array}{c}\text { Space group } \\
\text { symbol }\end{array}$ & $\begin{array}{c}\text { Structural } \\
\text { designation }\end{array}$ & $\begin{array}{c}\text { Pearson's } \\
\text { symbol }\end{array}$ \\
\hline LIQUID & Liquid & - & - & - \\
RHOMBO_A7 & $(\mathrm{Bi})$ & $R \overline{3} m H$ & $A 7$ & $h R 2$ \\
DIAMOND_A4 & $(\mathrm{Ge})$ & $F m \overline{3} m$ & $A 4$ & $c F 8$ \\
TETRAG_A6 & $(\mathrm{In})$ & $I 4 / m m m$ & $A 6$ & $t I 2$ \\
BIIN & $\mathrm{BiIn}$ & $P 4 / \mathrm{nmms}$ & $B 10$ & $t P 4$ \\
BI3IN5 & $\mathrm{Bi}{ }_{3} \mathrm{In}$ 5 & $I 4 / \mathrm{mcm}$ & $D 8_{1}$ & $t I 32$ \\
BIIN_BRASS & $\mathrm{BiIn}_{2}$ & $P 6_{3} / \mathrm{mmc}$ & $B 8_{2}$ & $h P 6$ \\
TET_ALPHA1 & $\varepsilon$ & $I 4 / \mathrm{mmm}$ & $A 6 m o d$ & $t I 2$ \\
\hline
\end{tabular}

According to the information listed in Table 1, stable phases that should appear in the ternary Bi-Ge-In system include liquid phase, solid solution phases (Bi), (Ge), (In) and $\varepsilon$, and three binary intermetallic compounds $\mathrm{BiIn}, \mathrm{Bi}_{3} \mathrm{In}_{5}$ and $\mathrm{BiIn}_{2}$. 


\section{Ternary Bi-Ge-In system}

Isothermal section at $200^{\circ} \mathrm{C}$

Five ternary samples were annealed at $200{ }^{\circ} \mathrm{C}$ for four weeks and then analyzed by using SEM-EDS and XRD techniques. The obtained results are summarized in Table 2.

Table 2. Combined results of SEM-EDS and XRD analyzes

of the selected Bi-Ge-In alloys annealed at $T=200{ }^{\circ} \mathrm{C}$.

\begin{tabular}{|c|c|c|c|c|c|c|c|c|}
\hline \multirow{2}{*}{$\mathrm{N}}$. & \multirow{2}{*}{$\begin{array}{c}\text { Composition } \\
\text { of samples } \\
\text { (at. \%) }\end{array}$} & \multicolumn{2}{|c|}{$\begin{array}{l}\text { Determined } \\
\text { phases }\end{array}$} & \multicolumn{3}{|c|}{ Compositions of phases (at. \%) } & \multicolumn{2}{|c|}{ Lattice parameters $(\AA)$} \\
\hline & & EDS & XRD & $\mathrm{Bi}$ & $\mathrm{Ge}$ & In & $a=b$ & $c$ \\
\hline 1. & $\begin{array}{l}9.36 \mathrm{Bi} \\
51.42 \mathrm{Ge} \\
39.22 \mathrm{In}\end{array}$ & $\begin{array}{l}\mathrm{L} \\
(\mathrm{Ge})\end{array}$ & $(\mathrm{Ge})$ & $\begin{array}{l}73.55 \pm 0.4 \\
0.83 \pm 0.1\end{array}$ & $\begin{array}{l}1.42 \pm 0.5 \\
98.45 \pm 0.3\end{array}$ & $\begin{array}{l}25.03 \pm 0.8 \\
0.72 \pm 0.9\end{array}$ & $5.6557 \pm 0.0004$ & \\
\hline 2. & $\begin{array}{l}23.69 \mathrm{Bi} \\
53.21 \mathrm{Ge} \\
23.10 \mathrm{In}\end{array}$ & $\begin{array}{l}\mathrm{L} \\
(\mathrm{Ge})\end{array}$ & $(\mathrm{Ge})$ & $\begin{array}{l}81.38 \pm 0.8 \\
0.14 \pm 0.2\end{array}$ & $\begin{array}{l}1.18 \pm 0.1 \\
99.05 \pm 0.2\end{array}$ & $\begin{array}{l}17.44 \pm 0.2 \\
0.81 \pm 0.2\end{array}$ & $5.6585 \pm 0.0006$ & \\
\hline 3. & $\begin{array}{l}26.84 \mathrm{Bi} \\
17.93 \mathrm{Ge} \\
55.23 \mathrm{In}\end{array}$ & $\begin{array}{l}\mathrm{L} \\
(\mathrm{Ge})\end{array}$ & $(\mathrm{Ge})$ & $\begin{array}{l}87.91 \pm 0.6 \\
0.67 \pm 0.7\end{array}$ & $\begin{array}{l}0.88 \pm 0.3 \\
98.71 \pm 0.5\end{array}$ & $\begin{array}{l}11.21 \pm 0.4 \\
0.62 \pm 0.2\end{array}$ & $5.6456 \pm 0.0003$ & \\
\hline 4. & $\begin{array}{l}44.35 \mathrm{Bi} \\
49.17 \mathrm{Ge} \\
6.48 \mathrm{In}\end{array}$ & $\begin{array}{l}\mathrm{L} \\
(\mathrm{Ge}) \\
(\mathrm{Bi})\end{array}$ & $\begin{array}{l}(\mathrm{Ge}) \\
(\mathrm{Bi})\end{array}$ & $\begin{array}{l}69.32 \pm 0.8 \\
0.50 \pm 0.4 \\
98.18 \pm 0.3\end{array}$ & $\begin{array}{l}3.18 \pm 0.1 \\
98.28 \pm 0.1 \\
0.98 \pm 0.8\end{array}$ & $\begin{array}{l}27.50 \pm 0.2 \\
1.22 \pm 0.8 \\
0.84 \pm 0.6\end{array}$ & $\begin{array}{l}5.6578 \pm 0.0001 \\
4.5565 \pm 0.0004\end{array}$ & $\begin{array}{l}11.8143 \\
\pm 0.0004 \\
\end{array}$ \\
\hline 5. & $\begin{array}{l}70.18 \mathrm{Bi} \\
10.85 \mathrm{Ge} \\
18.97 \mathrm{In}\end{array}$ & $\begin{array}{l}\mathrm{L} \\
(\mathrm{Ge}) \\
(\mathrm{Bi})\end{array}$ & $\begin{array}{l}(\mathrm{Ge}) \\
(\mathrm{Bi})\end{array}$ & $\begin{array}{l}71.98 \pm 0.4 \\
1.26 \pm 0.4 \\
97.87 \pm 0.7\end{array}$ & $\begin{array}{l}2.36 \pm 0.9 \\
98.25 \pm 0.6 \\
1.23 \pm 0.3\end{array}$ & $\begin{array}{l}25.66 \pm 0.4 \\
0.49 \pm 0.9 \\
0.90 \pm 0.7\end{array}$ & $\begin{array}{l}5.6821 \pm 0.0009 \\
4.5378 \pm 0.0002\end{array}$ & $\begin{array}{l}11.8345 \\
\pm 0.0006\end{array}$ \\
\hline
\end{tabular}

Within the five investigated samples, two different phase regions were detected. One is $\mathrm{L}+(\mathrm{Ge})$ two-phase region and one is $\mathrm{L}+(\mathrm{Ge})+(\mathrm{Bi})$ three-phase region. Samples 1 , 2 and 3 belong to the $\mathrm{L}+(\mathrm{Ge})$ phase region while samples 4 and 5 to the $\mathrm{L}+(\mathrm{Ge})+(\mathrm{Bi})$ phase region. As in samples 1-5, the content of the bismuth increases, from 9.36 at.\% (sample 1) to 70.18 at.\% (sample 5); this leads to the microstructural changes and appearance of $(\mathrm{Bi})$ solid solution in samples rich with $\mathrm{Bi}$. In all the samples $\mathrm{L}$ phase is stable, as well as the (Ge) solid solution. Nonetheless, the stability of (Bi) solid solution changes. So, in samples 4 and 5, (Bi) solid solution is stable. Determined lattice parameters of the $(\mathrm{Ge})$ and $(\mathrm{Bi})$ solid solutions are compared with literature values $[17$, $18]$.

SEM micrographs of microstructures of the two samples annealed at $200{ }^{\circ} \mathrm{C}$ are presented in Figure 1 as an illustration.

Phases detected by EDS and XRD analysis are marked on the given micrographs. The microstructure of sample 3 consists of two phases: $\mathrm{L}$ as a gray phase and $(\mathrm{Ge})$ solid solution as a dark phase. Sample 5 contains three phases in microstructure: L as a gray phase, $(\mathrm{Ge})$ solid solution as a dark phase and solid solution (Bi) as a dark gray phase.

Figure 2 shows a comparison of EDS results summarized in Table 2 and a calculated isothermal section at $200{ }^{\circ} \mathrm{C}$. The obtained experimental results are marked with the same symbol but in a different color to distinguish the results of different samples. 


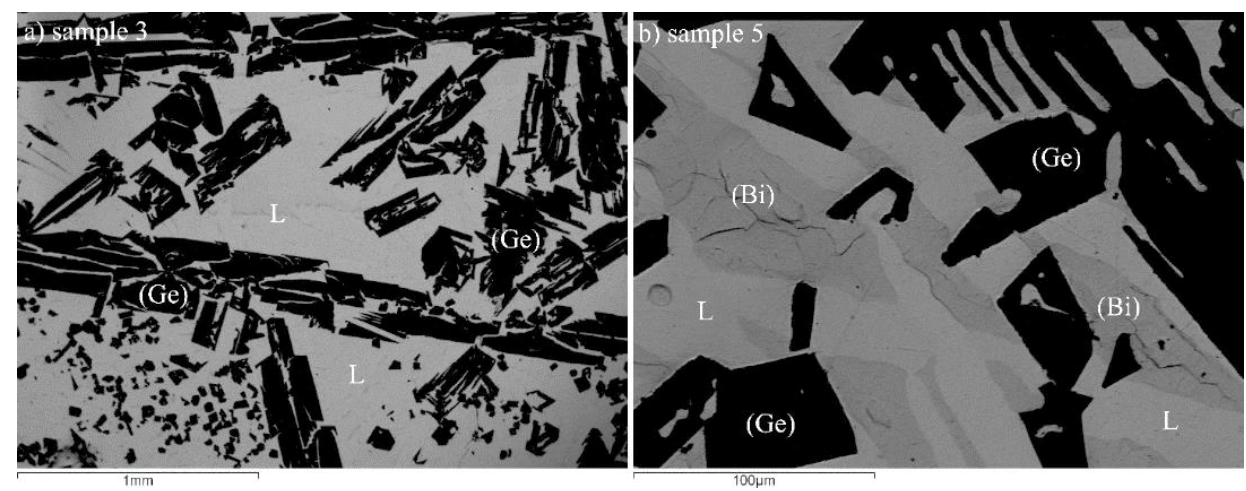

Fig. 1. SEM micrographs of the samples annealed at $200{ }^{\circ} \mathrm{C}$ a) sample 3 and b) sample 5 .

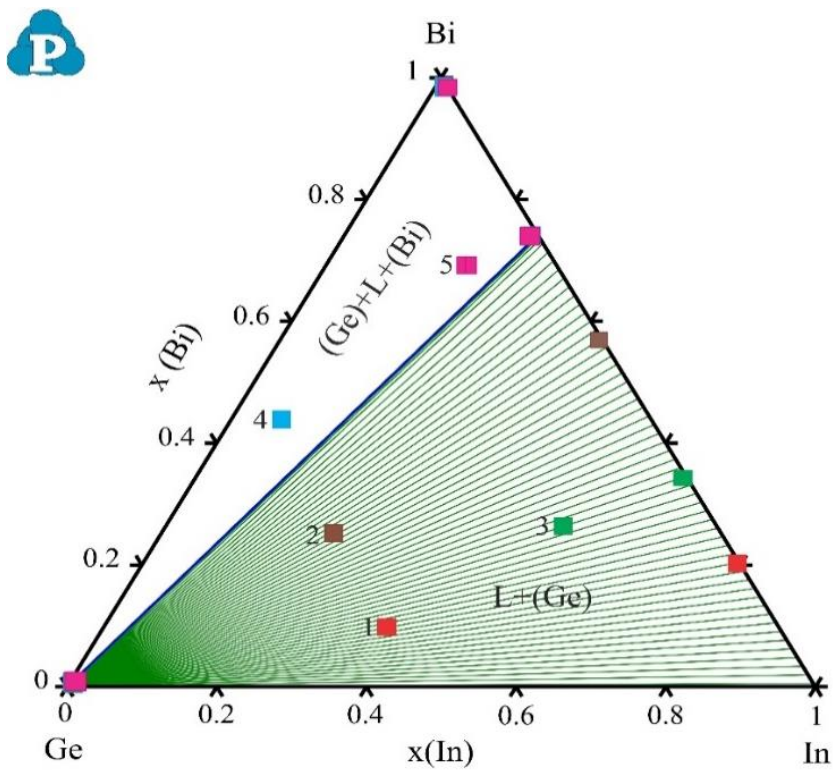

Fig. 2. The calculated isothermal section at $200^{\circ} \mathrm{C}$ compared with EDS results given in Table 2.

The calculated isothermal section at $200{ }^{\circ} \mathrm{C}$ consists of two different phase regions, one is two phase region $\mathrm{L}+(\mathrm{Ge})$ and the other is three phase region $(\mathrm{Ge})+\mathrm{L}+(\mathrm{Bi})$. Both were experimentally confirmed by analysis of the samples annealed at $200{ }^{\circ} \mathrm{C}$. Samples 1,2 , and 3 are located in $\mathrm{L}+(\mathrm{Ge})$ two-phase region, whereas samples 4 and 5 are located in $(\mathrm{Ge})+\mathrm{L}+(\mathrm{Bi})$ three-phase region, in the same phase regions as experimentally proved. 


\section{Isothermal section at $300^{\circ} \mathrm{C}$}

For the second selected isothermal section of Bi-Ge-In system at $300{ }^{\circ} \mathrm{C}$, five ternary samples annealed at $300{ }^{\circ} \mathrm{C}$ were experimentally analyzed and the obtained results (SEMEDS and XRD) are summarized in Table 3.

Table 3. Combined results of SEM-EDS and XRD analyzes of the selected Bi-Ge-In alloys annealed at $T=300{ }^{\circ} \mathrm{C}$.

\begin{tabular}{|c|c|c|c|c|c|c|c|}
\hline \multirow{2}{*}{ N. } & \multirow{2}{*}{$\begin{array}{l}\text { Composition } \\
\text { of samples } \\
(\text { at. \%) }\end{array}$} & \multicolumn{2}{|c|}{ Determined phases } & \multicolumn{3}{|c|}{ Compositions of phases (at. \%) } & \multirow{2}{*}{$\begin{array}{c}\text { Lattice } \\
\text { parameters }(\AA) \\
a=b=c\end{array}$} \\
\hline & & EDS & XRD & $\mathrm{Bi}$ & $\mathrm{Ge}$ & In & \\
\hline 1. & $\begin{array}{l}11.41 \mathrm{Bi} \\
65.14 \mathrm{Ge} \\
23.45 \mathrm{In} \\
\end{array}$ & $\begin{array}{l}\mathrm{L} \\
(\mathrm{Ge})\end{array}$ & $(\mathrm{Ge})$ & $\begin{array}{l}56.32 \pm 0.4 \\
1.65 \pm 0.6\end{array}$ & $\begin{array}{l}2.76 \pm 0.2 \\
97.66 \pm 0.1\end{array}$ & $\begin{array}{l}40.92 \pm 0.8 \\
0.69 \pm 0.8\end{array}$ & $5.6556 \pm 0.0002$ \\
\hline 2. & $\begin{array}{l}9.65 \mathrm{Bi} \\
39.84 \mathrm{Ge} \\
50.51 \mathrm{In}\end{array}$ & $\begin{array}{l}\mathrm{L} \\
(\mathrm{Ge})\end{array}$ & $(\mathrm{Ge})$ & $\begin{array}{l}66.67 \pm 0.6 \\
0.52 \pm 0.6\end{array}$ & $\begin{array}{l}0.83 \pm 0.5 \\
98.43 \pm 0.3\end{array}$ & $\begin{array}{l}32.50 \pm 0.2 \\
1.05 \pm 0.2\end{array}$ & $5.6512 \pm 0.0005$ \\
\hline 3. & $\begin{array}{l}29.96 \mathrm{Bi} \\
17.49 \mathrm{Ge} \\
52.55 \mathrm{In} \\
\end{array}$ & $\begin{array}{l}\mathrm{L} \\
(\mathrm{Ge})\end{array}$ & $(\mathrm{Ge})$ & $\begin{array}{l}45.78 \pm 0.1 \\
0.80 \pm 0.8\end{array}$ & $\begin{array}{l}1.24 \pm 0.7 \\
99.07 \pm 0.3\end{array}$ & $\begin{array}{l}52.98 \pm 0.2 \\
0.13 \pm 0.1\end{array}$ & $5.6435 \pm 0.0002$ \\
\hline 4. & $\begin{array}{l}46.45 \mathrm{Bi} \\
40.50 \mathrm{Ge} \\
13.05 \mathrm{In}\end{array}$ & $\begin{array}{l}\mathrm{L} \\
(\mathrm{Ge})\end{array}$ & $(\mathrm{Ge})$ & $\begin{array}{l}72.78 \pm 0.6 \\
0.98 \pm 0.7\end{array}$ & $\begin{array}{l}1.65 \pm 0.2 \\
98.08 \pm 0.1\end{array}$ & $\begin{array}{l}25.57 \pm 0.1 \\
0.94 \pm 0.6\end{array}$ & $5.6587 \pm 0.0006$ \\
\hline 5. & $\begin{array}{l}58.81 \mathrm{Bi} \\
10.85 \mathrm{Ge} \\
26.18 \mathrm{In}\end{array}$ & $\begin{array}{l}\mathrm{L} \\
(\mathrm{Ge})\end{array}$ & $(\mathrm{Ge})$ & $\begin{array}{l}83.34 \pm 0.7 \\
1.47 \pm 0.2\end{array}$ & $\begin{array}{l}0.78 \pm 0.6 \\
97.25 \pm 0.6\end{array}$ & $\begin{array}{l}15.88 \pm 0.5 \\
1.28 \pm 0.8\end{array}$ & $5.6556 \pm 0.0005$ \\
\hline
\end{tabular}

As shown in Table 5, in all tested samples, the same two phases $\mathrm{L}$ and (Ge) solid solution were detected. The EDS results show that $(\mathrm{Ge})$ solid solution is expectedly rich with germanium and dissolves a negligible amount of indium and bismuth. L phase is rich in bismuth and indium and dissolves a negligible amount of germanium.

SEM micrograph of the sample annealed at $300{ }^{\circ} \mathrm{C}$ is presented in Figure 3.

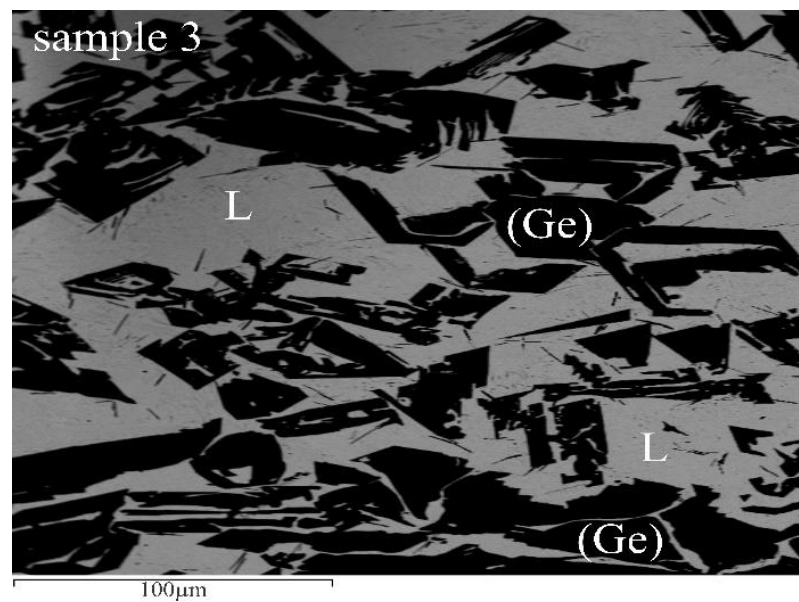

Fig. 3. SEM micrograph of the sample annealed at $300{ }^{\circ} \mathrm{C}$ (sample 3). 
Out of the two phases visible in the microstructure of sample 3 (Fig. 3) one is (Ge) solid solution and the other is L phase.

Since the tested samples were annealed at $300{ }^{\circ} \mathrm{C}$, EDS results of the tested samples (Table 3) are compared with a calculated isothermal section at $300{ }^{\circ} \mathrm{C}$. Figure 4 , presents the calculated isothermal section at $300{ }^{\circ} \mathrm{C}$ compared with the EDS results.

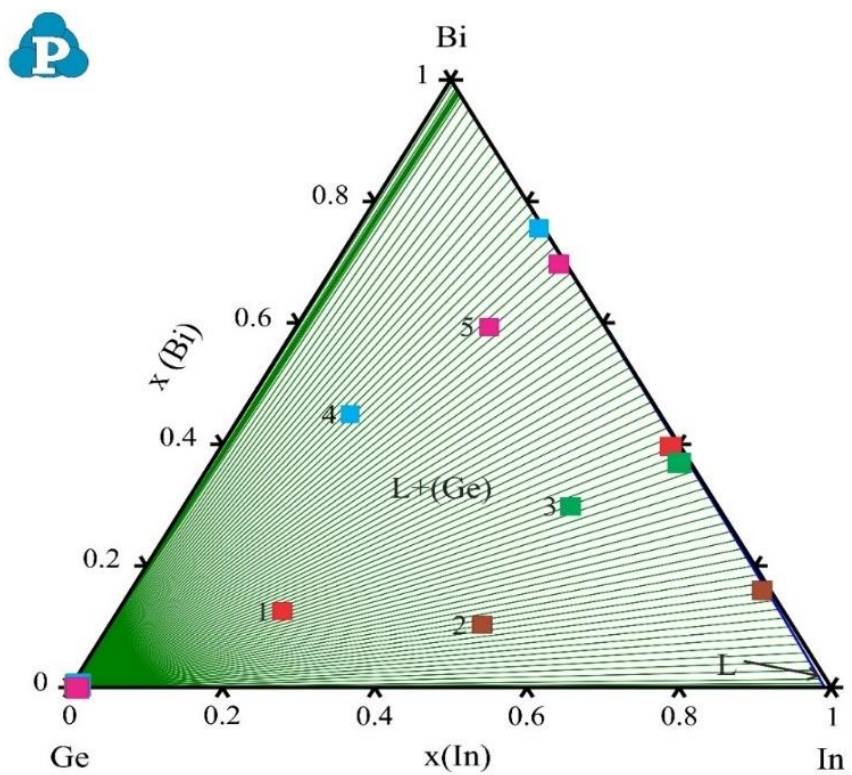

Fig. 4. The calculated isothermal section at $300^{\circ} \mathrm{C}$ compared with EDS results given in Table 3.

The calculated isothermal section at $300{ }^{\circ} \mathrm{C}$ consists of two phase regions. One is single phase region $\mathrm{L}$ and the other is two-phase region $\mathrm{L}+(\mathrm{Ge})$. All of the tested samples are located in two-phase region $\mathrm{L}+(\mathrm{Ge})$. EDS compositions of the phases are in close agreement with the calculated compositions of the phases.

Microstructural analysis of slowly-cooled samples

Light optical microscope was used for microstructure observations on 12 alloy samples. The samples' compositions are positioned along three vertical sections Bi-GeIn, Ge-BiIn, and In-BiGe. From each section, four samples were prepared and marked with numbers from 1 to 12 . The first four samples are from Bi-GeIn section; another four samples are from Ge-BiIn section and the samples marked from 9 to 12 are from In-BiGe section. Figure 5 shows compositions of the 12 studied ternary alloy samples and the calculated isothermal section at $25^{\circ} \mathrm{C}$. 


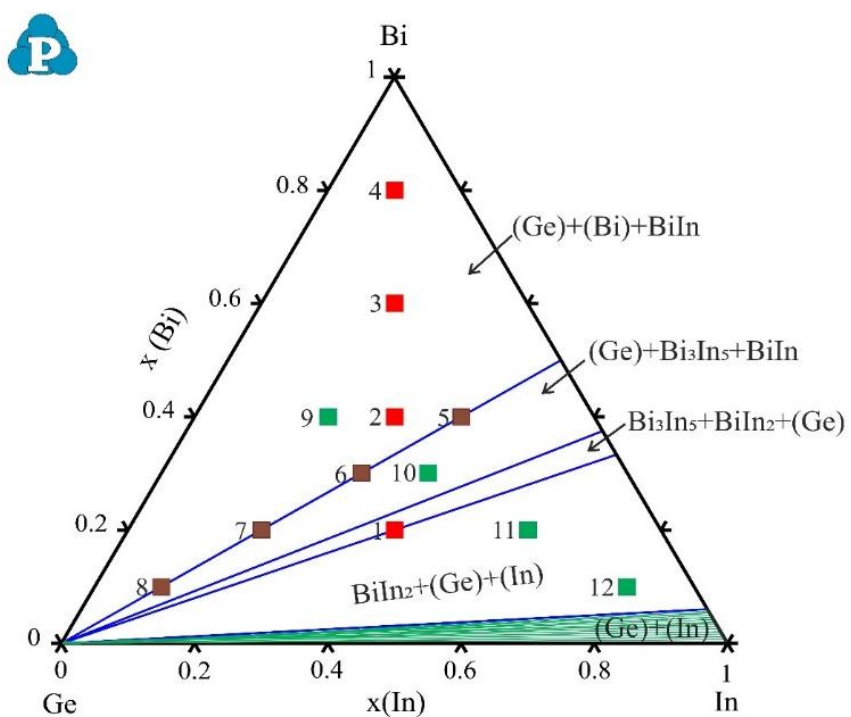

Fig. 5. The predicted isothermal section at $25^{\circ} \mathrm{C}$ and composition of 12 ternary samples.

According to the calculations, sample 1 belongs to the $\mathrm{BiIn}_{2}+(\mathrm{Ge})$ region, samples 2-4 and 9 to the $(\mathrm{Ge})+(\mathrm{Bi})+\mathrm{BiIn}$ region, samples 5-8 to the $(\mathrm{Ge})+\mathrm{BiIn}$, sample 10 to the $(\mathrm{Ge})+\mathrm{Bi}_{3} \mathrm{In}_{5}+\mathrm{BiIn}$ region, the samples marked with numbers 11 and 12 belong to the $\mathrm{BiIn}_{2}+(\mathrm{Ge})+(\mathrm{In})$ three-phase region. The obtained XRD results support these findings and are in agreement with calculated phase regions.

These samples were used for measurements of mechanical and electrical properties. Two microstructures of samples 2 and 11 are given in Figure 6.

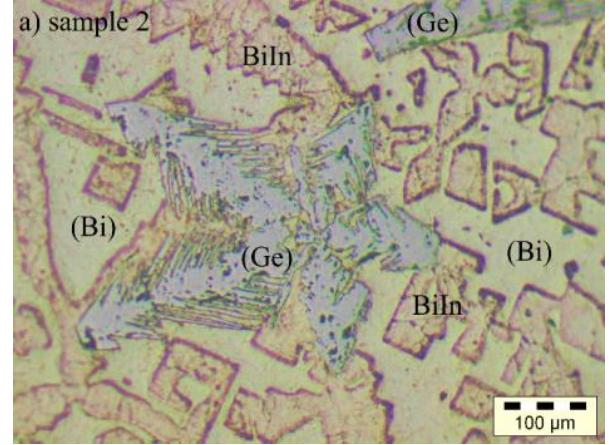

a)

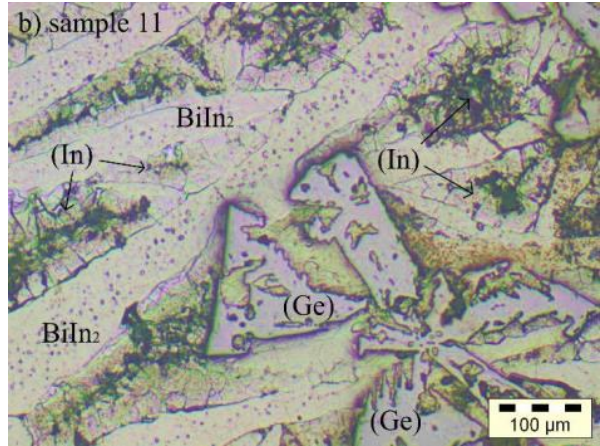

b)

Fig. 6. LOM micrographs of a) sample 2 and b) sample 11.

Phases that appear in microstructures are marked at presented micrographs. 


\section{Brinell hardness measurements}

Twelve ternary samples and three binary samples were subjected to the Brinell hardness measurements. Based on the repeated measurements, the mean values of Brinell hardness were calculated and presented in Table 4. Literature values of hardness for pure elements [19] are also shown in Table 4 for comparison.

Table 4. Compositions of the investigated samples at room temperature and measured Brinell hardness values.

\begin{tabular}{|c|c|c|c|c|c|c|c|}
\hline \multirow{2}{*}{ N. } & \multicolumn{3}{|c|}{ Alloy nominal composition (at.\%) } & \multicolumn{3}{|c|}{ Measured value $\left(\mathrm{MN} / \mathrm{m}^{2}\right)$} & \multirow{2}{*}{$\begin{array}{l}\text { Mean value } \\
\left(\mathrm{MN} / \mathrm{m}^{2}\right)\end{array}$} \\
\hline & $\mathrm{x}(\mathrm{Bi})$ & $\mathrm{x}(\mathrm{Ge})$ & $x(\operatorname{In})$ & 1 & 2 & 3 & \\
\hline B1 & 0 & 0.5 & 0.5 & 243.80 & 249.60 & 246.30 & 246.43 \\
\hline 1 & 0.2 & 0.4 & 0.4 & 7.30 & 7.10 & 7.20 & 7.20 \\
\hline 2 & 0.4 & 0.3 & 0.3 & 8.20 & 7.30 & 9.60 & 8.36 \\
\hline 3 & 0.6 & 0.2 & 0.2 & 9.60 & 10.10 & 9.30 & 9.66 \\
\hline 4 & 0.8 & 0.1 & 0.1 & 10.40 & 10.30 & 10.50 & 10.40 \\
\hline $\mathrm{Bi}$ & 1 & 0 & 0 & & & & $94.20[19]$ \\
\hline B2 & 0.5 & $\mathbf{0}$ & 0.5 & 93.20 & 94.10 & 92.30 & 93.20 \\
\hline 5 & 0.4 & 0.2 & 0.4 & 1.60 & 1.80 & 2.30 & 1.90 \\
\hline 6 & 0.3 & 0.4 & 0.3 & 4.80 & 3.60 & 3.30 & 3.90 \\
\hline 7 & 0.2 & 0.6 & 0.2 & 4.80 & 5.30 & 4.70 & 4.93 \\
\hline 8 & 0.1 & 0.8 & 0.1 & 9.80 & 10.00 & 11.60 & 10.46 \\
\hline $\mathrm{Ge}$ & 0 & 1 & 0 & & & & $973.40[19]$ \\
\hline B3 & 0.5 & 0.5 & 0 & 213.20 & 215.60 & 217.40 & 215.40 \\
\hline 9 & 0.4 & 0.4 & 0.2 & 9.30 & 7.80 & 8.30 & 8.46 \\
\hline 10 & 0.3 & 0.3 & 0.4 & 7.80 & 4.90 & 5.60 & 6.10 \\
\hline 11 & 0.2 & 0.2 & 0.6 & 4.90 & 4.60 & 4.50 & 4.66 \\
\hline 12 & 0.1 & 0.1 & 0.8 & 4.10 & 3.80 & 3.70 & 3.86 \\
\hline In & 0 & 0 & 1 & & & & 8.83 [19] \\
\hline
\end{tabular}

In addition to the tabular presentation, the obtained values for hardness are also presented graphically. Figure 7 shows a graphical representation of the relationship between the hardness and the composition of the tested alloys.

From the obtained results, shown in Table 4, as well as graphically shown in Figure 7 it can be seen that the binary samples $\mathrm{Ge}_{50} \mathrm{In}_{50}$ and $\mathrm{Bi}_{50} \mathrm{Ge}_{50}$ have the highest hardness values. Among the other tested ternary samples, the highest hardness value of 10.46 $\mathrm{MN} / \mathrm{m}^{2}$ was recorded for sample $8\left(\mathrm{Bi}_{10} \mathrm{Ge}_{80} \mathrm{In}_{10}\right)$, which is understandable due to the presence of high Ge content in the alloy. In this sample, two phases are stable $(\mathrm{Ge})+\mathrm{BiIn}$; however, the content of (Ge) solid solution phase is much higher than that of BiIn phase. These two phases are also stable in samples 5, 6, and 7 but in a different ratio. Depending on which phase predominates, BiIn or $(\mathrm{Ge})$ hardness is changing. So in sample 5 , the dominant phase is BiIn, and in sample 8 dominant phase is $(\mathrm{Ge})$. The lowest value of hardness of $1.90 \mathrm{MN} / \mathrm{m}^{2}$ was measured for sample $5\left(\mathrm{Bi}_{40} \mathrm{Ge}_{20} \mathrm{In}_{40}\right)$, due to the low content of Ge.

In general, it can be noticed that with an increase of the $\mathrm{Bi}$ and $\mathrm{Ge}$ content in $\mathrm{Bi}$ Ge-In ternary alloys, the hardness increases. Conversely, an increase of In content in the ternary samples leads to a slight decrease in the hardness. 
Response Surface Methodology - RSM was used to quantify the relationship between independent input parameters and the dependent variable (response) [20-24]. Data processing was done in the software package Design Expert v.9.0.6.2. By using the results given in Table 4, a mathematical model for Brinell hardness was developed. Using all possible canonicals or Scheffe models, a Special Cubic model has been suggested. The diagnosis of the statistical properties of the assumed model found that the distribution of residuals is not normal and that it is necessary to transform the mathematical model in order to meet the conditions of normality. The Box-Cox diagnostics recommends the "Inverse Square Root" transformation for the variance stabilization.

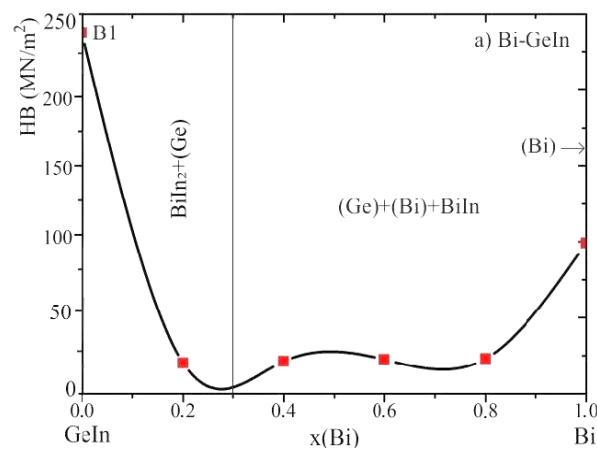

a)

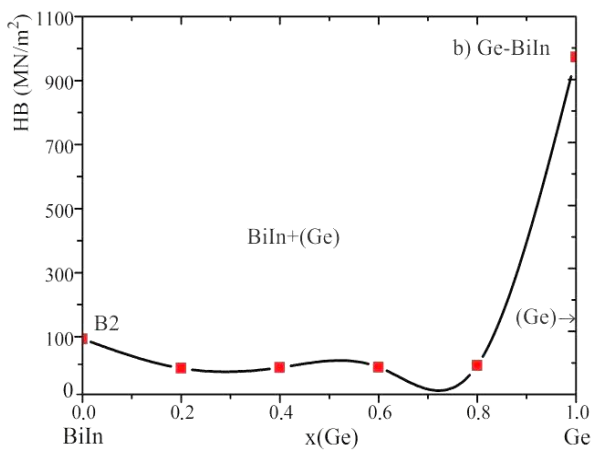

b)

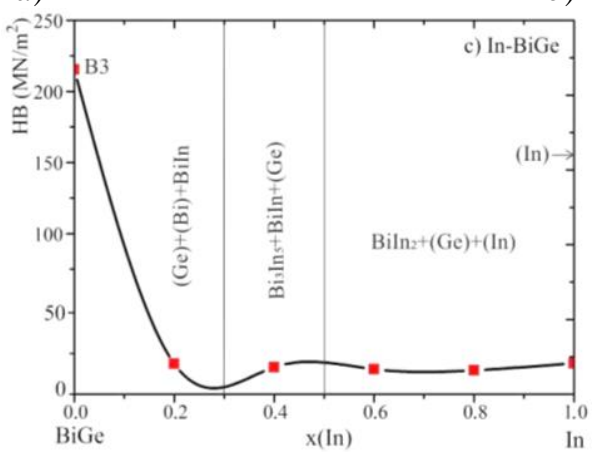

c)

Fig. 7. Graphical presentation of Brinell hardness vs. composition and phase fraction: a) vertical section Bi-GeIn, b) vertical section Ge-BiIn, and c) vertical section In-BiGe.

The final equation of the predictive model in terms of real components is (1):

$$
\begin{aligned}
& 1 / \mathrm{Sqrt}(\mathrm{HB}+1.00)=0.130602071 \cdot(\mathrm{Bi})+0.102462155 \cdot(\mathrm{Ge})+0.370110518 \cdot(\mathrm{In}) \\
& -0.05470384 \cdot(\mathrm{Bi}) \cdot(\mathrm{Ge})-0.31283672 \cdot(\mathrm{Bi}) \cdot(\mathrm{In})-0.44269865 \cdot(\mathrm{Ge}) \cdot(\mathrm{In}) \\
& \quad+9.202504558 \cdot(\mathrm{Bi}) \cdot(\mathrm{Ge}) \cdot(\mathrm{In})
\end{aligned}
$$

The repeated analysis for Inverse Square Root model transformation confirms the significance of the Transformed Special Cubic model. In this case, ANOVA confirms the Reduced Special Cubic Mixture model (Table 5). 
Table 5. ANOVA for Special Cubic Mixture model.

\begin{tabular}{llllll}
\hline Source & Sum of Squares & df & Mean Square & $\begin{array}{l}\text { F } \\
\text { Value }\end{array}$ & $\begin{array}{l}\text { p-value } \\
\text { Prob > F }\end{array}$ \\
\hline Model & 0.2976 & 6 & 0.0496 & 4.3057 & 0.0177 \\
Linear Mixture & 0.0626 & 2 & 0.0313 & 2.7185 & 0.1098 \\
AB & 0.0001 & 1 & 0.0001 & 0.0115 & 0.9167 \\
AC & 0.0043 & 1 & 0.0043 & 0.3747 & 0.5529 \\
BC & 0.0086 & 1 & 0.0086 & 0.7504 & 0.4048 \\
ABC & 0.1338 & 1 & 0.1338 & 11.6180 & 0.0058 \\
Residual & 0.1267 & 11 & 0.0115 & & \\
Cor Total & 0.4243 & 17 & & & \\
\hline
\end{tabular}

The F-value of the Model is 4.30. R-squared and other statistics values are listed in Table 6.

Table 6. R-squared and other statistics after the ANOVA.

\begin{tabular}{llll}
\hline Std. Dev. & 0.10733 & R-Squared & 0.70137 \\
Mean & 0.29367 & Adj R-Squared & 0.53847 \\
C.V. \% & 36.54931 & Pred R-Squared & 0.36179 \\
PRESS & 0.68656 & Adeq Precision & 5.24704 \\
\hline
\end{tabular}

The diagnosis of the statistics shows that the distribution of residuals is normal. The value of $\lambda$ is -0.5 , the optimum value of $\lambda$ is -0.37 and the $95 \%$ confidence interval for $\lambda$ (Low C.I. $=-0.76$, High C.I.=-0.01) contains the value -0.5 , thus proving the justification of the model transformation (Figure 8). 


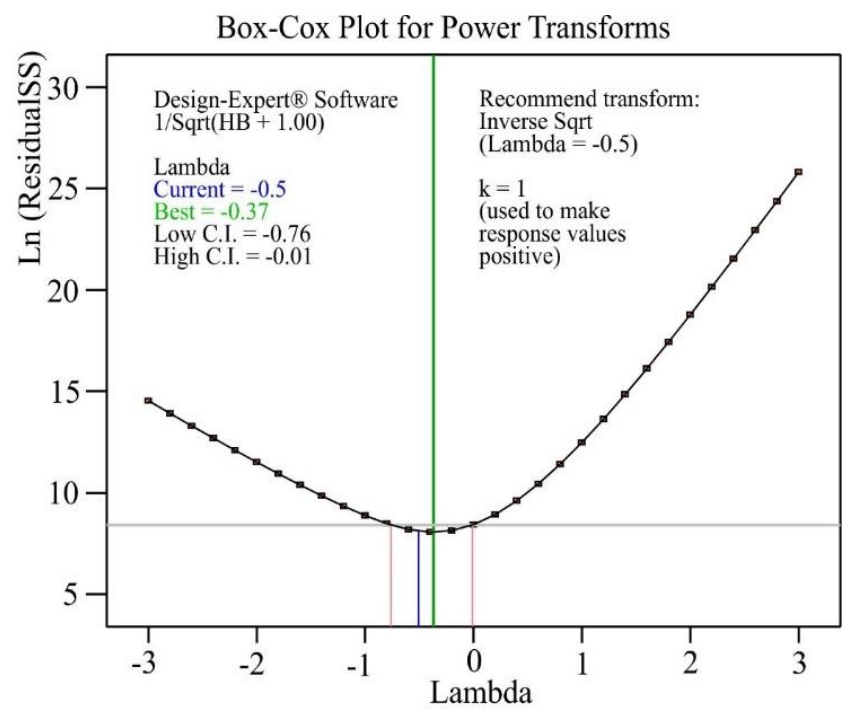

Figure 8. The Box-Cox plot for power transforms.

Figure 9 shows Brinell hardness defined by equation 1 .

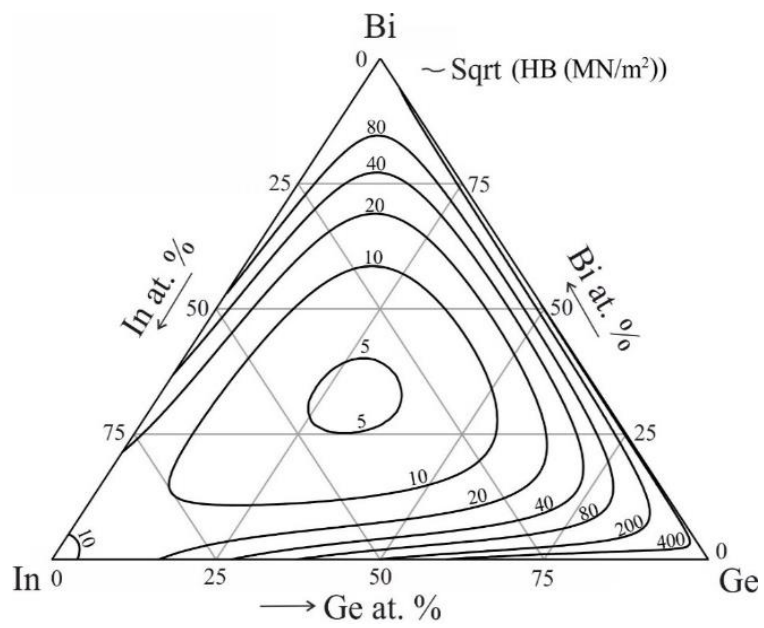

Fig. 9. Calculated iso-lines of Brinell hardness in ternary Bi-Ge-In system with $R^{2}=0.701$.

\section{Electrical conductivity measurements}

Measurements of electrical conductivity were performed on the same group of samples used for the hardness test, and the results are given in Table 7. Besides measured values, Table 7 also includes calculated mean values and literature values of electrical conductivity for pure elements [25]. 
Table 7. Compositions of the investigated samples at room temperature and the measured electrical conductivity values.

\begin{tabular}{|c|c|c|c|c|c|c|c|c|}
\hline \multirow{2}{*}{$\mathrm{N}}$. & \multicolumn{3}{|c|}{$\begin{array}{l}\text { Alloy nominal composition } \\
\text { (at.\%) }\end{array}$} & \multicolumn{4}{|c|}{ Value (MS /m) } & \multirow{2}{*}{$\begin{array}{l}\text { Mean value } \\
(\mathrm{MS} / \mathrm{m})\end{array}$} \\
\hline & $\mathrm{x}(\mathrm{Bi})$ & $\mathrm{x}(\mathrm{Ge})$ & $\mathrm{x}(\mathrm{In})$ & 1 & 2 & 3 & 4 & \\
\hline B1 & 0 & 0.5 & 0.5 & 3.6362 & 3.8328 & 3.4332 & 3.5983 & 3.6251 \\
\hline 1 & 0.2 & 0.4 & 0.4 & 0.3169 & 0.3200 & 0.3098 & 0.3182 & 0.3162 \\
\hline 2 & 0.4 & 0.3 & 0.3 & 0.3233 & 0.3180 & 0.3193 & 0.3158 & 0.3191 \\
\hline 3 & 0.6 & 0.2 & 0.2 & 0.3222 & 0.3193 & 0.3281 & 0.3233 & 0.3232 \\
\hline 4 & 0.8 & 0.1 & 0.1 & 0.3396 & 0.3289 & 0.3401 & 0.3395 & 0.3370 \\
\hline $\mathrm{Bi}$ & 1 & 0 & 0 & & & & & $0.77[25]$ \\
\hline B2 & 0.5 & 0 & 0.5 & 0.2630 & 0.2840 & 0.2990 & 0.2380 & 0.2710 \\
\hline 5 & 0.4 & 0.2 & 0.4 & 0.2935 & 0.3159 & 0.3269 & 0.3278 & 0.3160 \\
\hline 6 & 0.3 & 0.4 & 0.3 & 0.3385 & 0.3289 & 0.3258 & 0.3188 & 0.3280 \\
\hline 7 & 0.2 & 0.6 & 0.2 & 0.3366 & 0.3419 & 0.3313 & 0.3487 & 0.3396 \\
\hline 8 & 0.1 & 0.8 & 0.1 & 0.3596 & 0.3623 & 0.3496 & 0.3554 & 0.3567 \\
\hline $\mathrm{Ge}$ & 0 & 1 & 0 & & & & & $0.002[25]$ \\
\hline B3 & 0.5 & 0.5 & 0 & 0.3430 & 0.3410 & 0.3530 & 0.3440 & 0.3452 \\
\hline 9 & 0.4 & 0.4 & 0.2 & 0.3555 & 0.4189 & 0.4266 & 0.3999 & 0.4002 \\
\hline 10 & 0.3 & 0.3 & 0.4 & 0.6540 & 0.6799 & 0.6702 & 0.6635 & 0.6669 \\
\hline 11 & 0.2 & 0.2 & 0.6 & 0.9630 & 0.9562 & 0.9988 & 1.1023 & 1.0050 \\
\hline 12 & 0.1 & 0.1 & 0.8 & 1.4530 & 1.6140 & 1.5030 & 1.6483 & 1.5545 \\
\hline In & 0 & 0 & 1 & & & & & 12 [25] \\
\hline
\end{tabular}

For a more straightforward overview of the results, Figure 10 presents a graphical presentation of the obtained results (mean values) given in Table 7.

It is known that the chemical composition of alloys has a strong influence on electrical conductivity. In the studied ternary Bi-Ge-In alloys, a high value of electrical conductivity was detected in alloys with a high amount of indium. Out of the studied ternary samples, the highest electrical conductivity of $1.5545 \mathrm{MS} / \mathrm{m}$ was obtained for $\mathrm{Bi}_{10} \mathrm{Ge}_{10} \mathrm{In}_{80}$ alloy. However, in addition to the composition of the alloy, the phase components and their amount can also significantly affect the electrical conductivity. For example, in samples 11 and 12 the same three phases are in equilibrium $\operatorname{BiIn}_{2},(\mathrm{Ge})$, and (In). In samples 11 and 12, ratios between $\operatorname{BiIn}_{2},(\mathrm{Ge})$, and (In) is different, and this has a direct effect on the electrical conductivity. So in sample 12 where (In) solid solution phase is dominant electrical conductivity is high.

A quadratic Mixture model was suggested as a final equation for the prediction of electrical conductivity. The distribution of residuals is not normal and that it is necessary to transform the mathematical model in order to meet the conditions of normality. The Box-Cox diagnostics recommends the "Natural Log" transformation for the variance stabilization. 


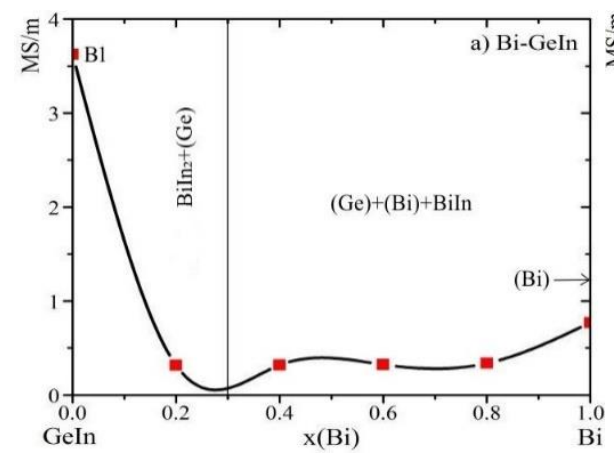

a)

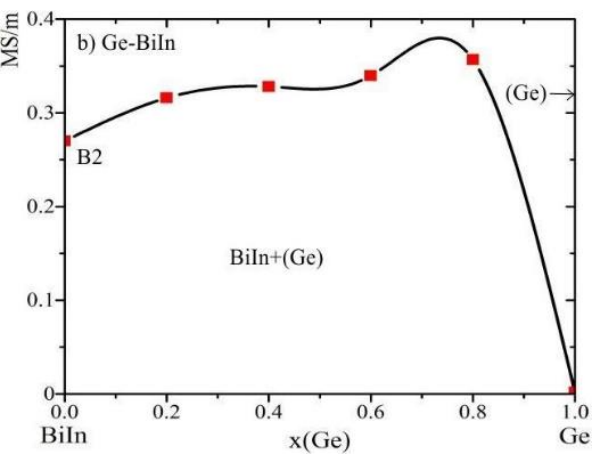

b)

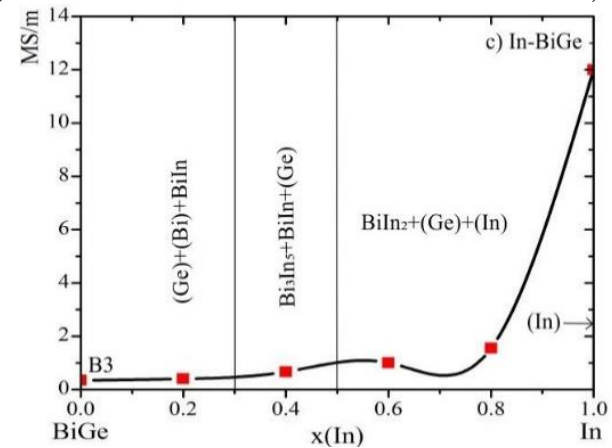

c)

Fig. 10. Graphical presentation of electrical conductivity vs. composition and phase fraction a) vertical section Bi-GeIn, $b$ ) vertical section $G e$-BiIn, and c) vertical section In-BiGe.

The final equation of the predictive model in terms of Real components is:

$$
\begin{aligned}
& \operatorname{Ln}(\sigma+0.10)=-0.0125953 \cdot(\mathrm{Bi})-1.9440351 \cdot(\mathrm{Ge})+2.2392631 \cdot(\mathrm{In})- \\
& 9.6950768 \cdot(\mathrm{Bi}) \cdot(\mathrm{In})+2.8577311 \cdot(\mathrm{Ge}) \cdot(\text { In })
\end{aligned}
$$

The repeated analysis for Natural Log model transformation confirms the significance of the Transformed Quadratic Mixture model. In this case, ANOVA confirms the adequacy of the Quadratic Mixture model (Table 8).

Table 8. ANOVA for Quadratic Mixture model.

\begin{tabular}{llllll}
\hline Source & Sum of Squares & df & Mean Square & F Value & $\begin{array}{l}\text { p-value } \\
\text { Prob > F }\end{array}$ \\
\hline Model & 16.56761 & 4 & 4.1419 & 32.93354 & 0.000001 \\
Linear Mixture & 10.58847 & 2 & 5.2942 & 42.09611 & 0.000002 \\
AC & 5.79625 & 1 & 5.7962 & 46.08778 & 0.000013 \\
BC & 0.50360 & 1 & 0.5036 & 4.00429 & 0.066712 \\
Residual & 1.63495 & 13 & 0.1258 & & \\
Cor Total & 18.20256 & 17 & & & \\
\hline
\end{tabular}


The F-value of the Model is 32.93 and it implies that the model is significant. Rsquared and other statistics after the ANOVA have good values, which confirm the justification of the choice of the adopted mathematical model (Table 9).

Table 9. R-squared and other statistics after the ANOVA.

\begin{tabular}{llll}
\hline Std. Dev. & 0.35463 & R-Squared & 0.91018 \\
Mean & -0.41859 & Adj R-Squared & 0.88254 \\
C.V. \% & 84.72114 & Pred R-Squared & 0.72134 \\
PRESS & 5.07231 & Adeq Precision & 22.38151 \\
\hline
\end{tabular}

The diagnosis of the statistical properties shows that the distribution of residuals is normal. The value of $\lambda$ is 0.0 , the optimum value of $\lambda$ is -0.14 and the $95 \%$ confidence interval for $\lambda$ (Low C.I. $=-0.42$, High C.I. $=0.13$ ) contains the value 0.0 , thus proving the justification of the model transformation (Figure 11).

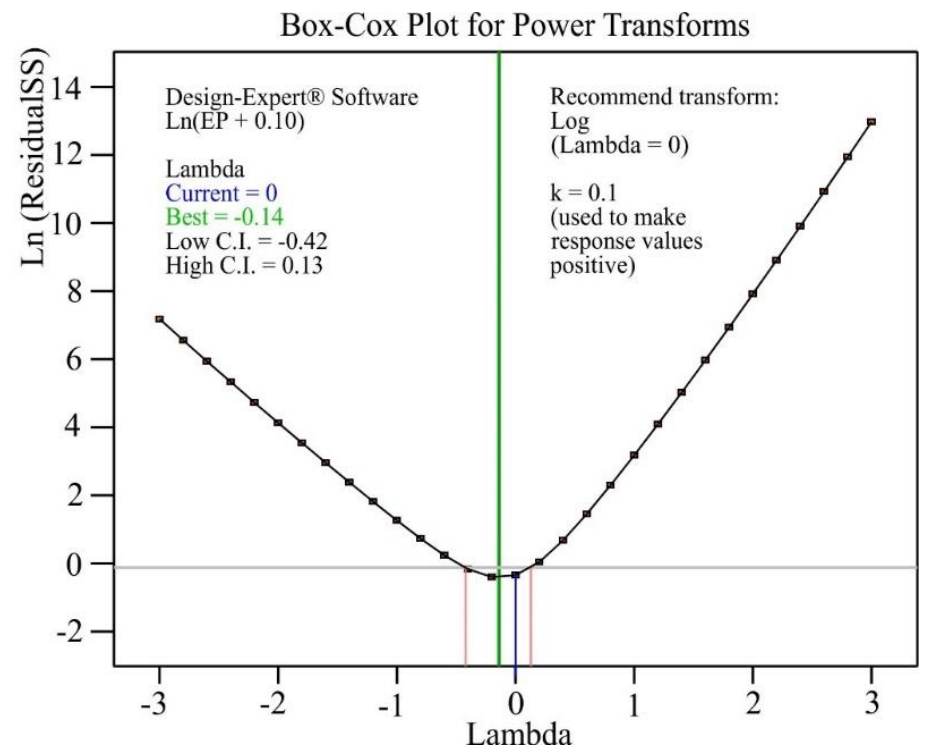

Fig. 11. The Box-Cox plot for power transforms.

Iso-lines contour plot for Electrical conductivity of Bi-Ge-In alloys defined by equation 1 is shown in Fig. 12. 


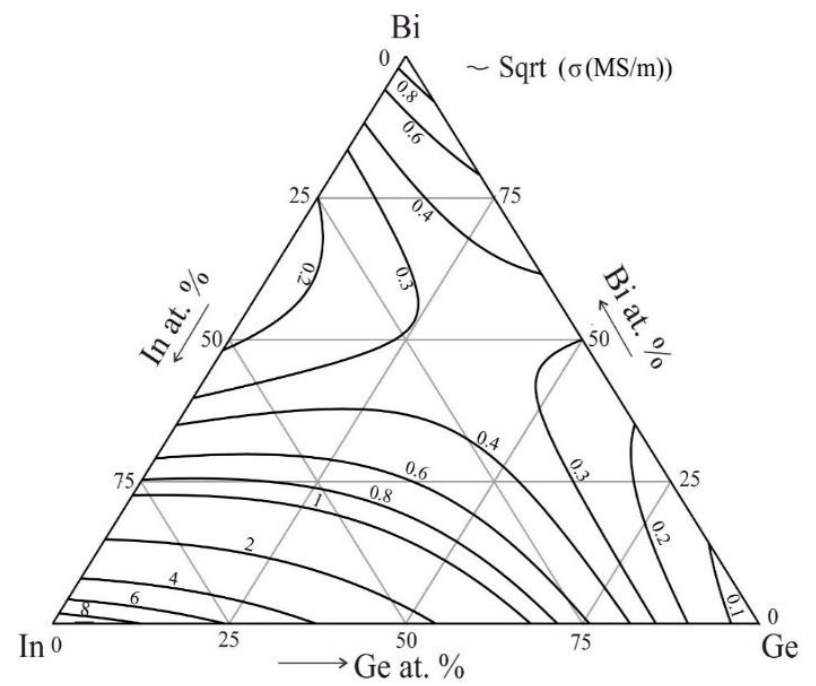

Fig. 12. Calculated iso-lines of Electrical conductivity in the ternary Bi-Ge-In system with $R^{2}=0.91$.

\section{Conclusion}

The ternary Bi-Ge-In system has been experimentally investigated by using appropriate experimental techniques. The EDS results were matched to the calculated isothermal sections at $200{ }^{\circ} \mathrm{C}$ and $300{ }^{\circ} \mathrm{C}$, and a close agreement was observed. The existence of a ternary compound was not detected in the tested ternary samples. On the same alloy samples, microstructural, hardness, and electrical conductivity tests were performed. Experimentally determined phases by XRD analysis were compared with the calculated isothermal section at $25{ }^{\circ} \mathrm{C}$, and agreement between the results was reached. By using ANOVA analysis and the experimentally obtained Brinell hardness and electrical conductivity values, an appropriate mathematical model was suggested to calculate properties along with each composition range.

\section{Acknowledgments}

This work has been supported by the National Natu+32re Science Foundation of China (Project No.51950410600) and the Ministry of Education, Science and Technological Development of the Republic of Serbia (Grant No. OI172037).

\section{References}

[1] A. Djordjević, D. Minić, M. Premović, D. Manasijević, V. Ćosović: JPED, 40 (4) (2019) 623-637.

[2] W. Cao, S. L. Chen, F. Zhang, K. Wu, Y. Yang, Y. A. Chang, R. Schmid-Fetzer, W. A. Oates: Calphad, 33(2) (2009) 328-342.

[3] G. W. Burr, B. N. Kurdi, J. C. Scott, C. H. Lam, K. Gopalakrishnan, R.S. Shenoy: IBM J Res Dev, 52(4-5) (2008) 449-464.

[4] T. C. Chong, X. Hu, L. P. Shi, P. K. Tan, X. S. Miao, R. Zhao: Jpn. J Appl Phys, 42 (2B) (2003) 824-827. 
[5] J. Solis, C.N. Afonso, J.F. Trull, and M.C. Morilla: J Appl Phys, 75 (12) (1994) 7788-7793.

[6] S. Raoux and T.J. Ibm, Phase Change Memory (PCM) Materials and Devices Y. Nishi, Ed., 2nd ed., Advances in Nonvolatile Memory and Storage Technology, 2014, 161-199.

[7] T. Siegrist, P. Jost, H. Volker, M. Woda, P. Merkelbach, C. Schlockermann, M. Wuttig: Nat Mater, 10 (2011) 202-208.

[8] N. Yamada, E. Ohno, N. Akahira, K. Nishiuchi, K. Nagata, M. Takao: Jpn J Appl Phys, 26 (1987) 61-66.

[9] M. Premović, D. Minić, V. Cosović, D. Manasijević, D. Živković: Metall Mater Trans A, 45A (2014) 4829-4841.

[10] D. Milisavljević, D. Minić, M. Premović, D. Manasijević, V. Ćosović, N. Košanin: Int J Thermophys, 40 (3) (2019) 29-42.

[11] C. Sinn-wen, H. Yohanes, G. Wojciech, W. Chao-hong, L. Shi-ting: Calphad, 68 (2020) 101744.

[12] R. Novakovic, E. Ricci, D. Giuranno, T. Lanata, S. Amore: Calphad, 33 (2009) 69-75.

[13] V.T. Witusiewicz, U. Hecht, B. Böttger, S. Rex: J Alloys Compounds, 428 (2007) 115-124.

[14] D. Boa, I. Ansara: Thermochim Acta, 314 (1998) 79-86.

[15] P. Y. Chevalier: Thermochim Acta, 155 (1989) 227-240.

[16] P. Y. Chevalier: Thermochim Acta, 132 (1988) 111-116.

[17] A. S. Cooper: Acta Cryst, 15 (1962) 578-582.

[18] P. Cucka, C. S. Barrett: Acta Cryst, 15 (1962) 865-875.

[19] http://periodictable.com/Properties/A/BrinellHardness.al.html, access 29.11.2018

[20] M. J. Anderson, P. J. Whitcomb, RSM Simplified, Optimizing Processes Using Response Surface Methods for Design of Experiments, Second Edition, CRC Press, Taylot \& Francis Group, 2017.

[21] G. E. P. Box, N. R. Draper, Response Surfaces, Mixtures, and Ridge Analyses, Second Edition, Wiley, 2007.

[22] Stat-Ease, Handbook for Experimenters, Version 11.00, Stat-Ease, Inc. 2018.

[23] D. C. Montgomery, Design and Analysis of Experiments, Ninth Edition, Wiley, 2017.

[24] R. H. Myers, D. C. Mongomery, C. M. Anderson-Cook, Response Surface Methodology, Process and Product Optimization Using Designed Experiments, Fourth Edition, Wiley, 2016.

[25] http://periodictable.com/Properties/A/ElectricalConductivity.an.html, access 25.12.2018.

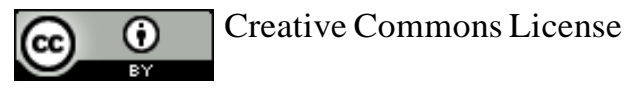

This work is licensed under a Creative Commons Attribution 4.0 International License. 